Gounon, A., Letort, J., Cotton, F., Weatherill, G., Sylvander, M., Latour, S. (2022): Improving depth estimations of African earthquakes using teleseismic data, and influence for the EastAfrican rift seismic hazard characterization. - Geophysical Journal International, 228, 1, 447-460.

https://doi.org/10.1093/gji/ggab348 


\title{
Improving depth estimations of African earthquakes using teleseismic data, and influence for the East-African rift seismic hazard characterization
}

\author{
Alisson Gounon, ${ }^{1}$ Jean Letort, ${ }^{1}$ Fabrice Cotton, ${ }^{2}$ Graeme Weatherill, ${ }^{2}$ \\ Matthieu Sylvander ${ }^{1}$ and Soumaya Latour ${ }^{1}$ \\ ${ }^{1}$ Observatoire Midi Pyrénées, IRAP, CNRS UMR 5277, Université Paul Sabatier, Toulouse 31400, France. E-mail: alisson.gounon@irap.omp.eu \\ ${ }^{2}$ GFZ German Research Centre for Geosciences Potsdam, Potsdam D-14473, Germany
}

Accepted 2021 August 27. Received 2021 July 21; in original form 2020 November 30

\begin{abstract}
SUMMAR Y
Well-constrained earthquake depth estimations are important for seismic hazard determination. As local networks of the East-African Rift are usually too sparse for reliable depth estimations, we used detections of $\mathrm{pP}$ and $\mathrm{sP}$ phase arrivals (the so-called depth phases) at teleseismic distance to constrain earthquake depths in this region. We rely on a fully automatic Cepstral analysis approach, first validated at the global scale using the ISC-EHB catalogue, then applied on the East-African seismicity. We investigated 9575 earthquakes from magnitude 2 since 2005 which allows us to constrain the depth estimation of 584 events with magnitude mainly above 3.5, complemented by 139 reliable depth estimations from previous studies based on teleseismic data as well. To ensure a final catalogue as complete as possible, we also identified from regional catalogues 113 earthquakes assumed to be well constrained, based on network geometry empirical criteria. Thanks to this study, we finally propose new earthquake depth distributions for the seismic source zonation defined by Poggi et al., in order to estimate the seismic hazard of the East African Rift region. Including those new distributions in the source models leads to significant changes of seismic hazard assessments results.
\end{abstract}

Key words: Africa; Body waves; Earthquake hazards.

\section{INTRODUCTION}

The seismicity of the eastern part of Africa is moderate, with earthquake magnitude generally below 6 , and is mainly due to the presence of the East African Rift System. Poggi et al. (2017) estimated the seismic hazard map for this area, but without an exhaustive study of earthquake depth distributions. The common practice in the characterization of seismic hazard is indeed to take into account the focal depth only indirectly, via the modification it implies on the source-site distance.

However, it is usually assumed that focal depth should play a more important role in seismic hazard assessment. For instance, depth estimation is known to have an incidence on peak ground acceleration values (e.g. Douglas 2001; Derras et al. 2012) and on intensity (e.g. Stromeyer \& Grunthal 2009). Nevertheless, few studies have analysed the impact of earthquake depth estimation on seismic hazard characterization, often because the depth parameter is poorly constrained during earthquake localisation procedures (Bondár et al. 2004). Furthermore, depth estimation is especially challenging for regions with sparse networks, as is the case for Africa.

The goal of this study is then to propose more reliable earthquake depth estimations based on teleseismic data, as originally proposed by Craig et al. (2011). These authors used two approaches to determine 227 well-constrained depth estimations from teleseismic data only, for the years 1964-2010, encompassing the whole African continent. For $M_{\mathrm{w}}>6$ events, they applied a waveform inversion procedure to estimate both depth and focal mechanism. For smaller magnitude events, they relied on P-pP and P-sP delays to constrain depth estimations. Here, we propose to analyse the more recent seismicity (2005-2019), relying on the Cepstral analysis proposed by Letort et al. (2015) to automatically detect and identify depth phase arrivals among the hundreds of available stations at teleseismic distance for each event.

This Cepstral method, detailed in the following part (2), allows for the processing of large data amounts from stations all around the world, and has been validated on various but specific case studies, (e.g. Mexico, Letort et al. 2015; Nepal, Letort et al. 2016) but never at the scale of a whole continent. Craig (2019) show that is possible to process automatically seismic data on large scale area. We hence first tested the ability of the Cepstral method to deal with large areas, by an application for worldwide earthquakes belonging to ISCEHB catalogue assumed to be well constrained at $\pm 5 \mathrm{~km}$ (L1-ISCEHB events, see Weston et al. 2018). Then, we used our procedure for depth estimation on all detected earthquakes with magnitude 
above 2 that occurred between 2005 and 2019 on the East African Rift System.

As teleseismic depth estimation can be limited for shallow events (Letort et al. 2014), 113 assumed reliable depth estimations are also extracted from regional localisations after a drastic selection on ISC bulletin (International Seismological Centre 2020a) from resolution criteria based on local seismic network geometry and number of detected phases. Indeed, several authors have shown that well-located events can be identified according to the network geometry used for the localisation process and have proposed empirical criteria for depth resolution (Bondár et al. 2004; Husen \& Hardebeck 2010; Bondár \& Storchak 2011; Letort et al. 2016; Theunissen et al. 2018). We finally provide a catalogue of 836 earthquakes, mostly with events constrained at teleseismic distances (723) and supplemented by these 113 regional catalogue events. We then discuss uncertainties and representativeness of the depth distributions for different areas. We finally re-evaluate the East-African Rift seismic hazard, through the use of OpenQuake computational tools (Pagani et al. 2014), taking exactly the same settings as defined by Poggi et al. (2017), but revising the depth distributions used in the source model. The impact of source depth distributions on the seismic hazard is finally debated.

\section{CEPSTRAL METHOD}

The teleseismic approach is well suited for studying African earthquakes, as few local networks are generally available (Craig et al. 2011). Teleseismic $P$-wave data are a mix of the direct $P$, reflected $\mathrm{pP}$ and $\mathrm{sP}$ wave arrivals, but can also have complex coda wave arrivals, and/or wave arrivals reflected from unconstrained smallscale heterogeneities in the crust and upper mantle. The identification and manual picking of these depth phases can hence be very challenging.

To overcome this limitation, we can rely on (1) an automatic picking procedure based on a Cepstral analysis (Letort et al. 2015) and (2) the validation of these pickings from the redundancy of coherent information through an important number of teleseismic stations (Letort et al. 2018). Moreover, the number of available stations and arrays in the world has significantly increased over the last decades, most of them concentrated in the Northern Hemisphere, providing thousands of stations at teleseismic distance for African regions and in all ranges of azimuths (Fig. 1).

The automatic Cepstral picking procedure has already proved its efficiency in several tectonic contexts (Letort et al. 2014, 2015, 2016). However, it was always at local scale, with a careful selection of stations and arrays to be used for each studied area. One step ahead, Letort et al. (2018) proposed to scan all available stations on the IRIS datacenter to extract automatically the recordings to be used for depth estimation, from SNR (signal to noise ratio) criteria and cepstral peaks criteria. It allowed them to blindly identify approximately 450 stations with clear and coherent $\mathrm{pP}, \mathrm{sP}$ detections for the 12 September 2016 event in South Korea, allowing for a more tightly constrained depth estimation.

This new approach (i.e. scanning automatically thousands of stations followed by completely blind station selection and depth estimation) has never been tested at the scale of a whole continent. Before applying it to the East African Rift earthquakes, we thus compare depth localisations of worldwide earthquakes obtained by Cepstral method to locations from the ISC-EHB catalogue (with depth phases picked by hand), for Level 1 (L1) events. L1-Event depths are labelled as well-constrained by the ISC. They have a free depth solution with a standard depth error less than $5 \mathrm{~km}$ and at least 3 depth phases (Weston et al. 2018) or fixed depth constrained by depth phases or by the USGS broad-band solution. It makes the L1-ISC-EHB catalogue an interesting tool to evaluate our independent depth estimations. One year of seismicity has been treated: the year 2012, with 497 events in the L1-ISC-EHB catalogue.

\subsection{Cepstral teleseismic depth estimation}

For each event, all the available teleseismic short-period data were downloaded through the IRIS Wilber 3 system (https://ds.iris.edu/wi lber3/) or IRIS Web Services (https://service.iris.edu/) web service. A time window of $100 \mathrm{~s}$ is automatically selected $5 \mathrm{~s}$ before the theoretical $P$-wave arrival, estimated using the ak 135 velocity model (Kennett et al. 1995) and $95 \mathrm{~s}$ after. The data are systematically bandpass filtered between 0.8 and $2.5 \mathrm{~Hz}$. Following Letort et al. (2018), an SNR criterion is then defined based on a power spectrum maxima ratio of two windows before and after the theoretical arrival time of the direct $P$ wave, allowing to reject noisy recordings. Then, cepstra functions are estimated, still following Letort et al. (2018). For each of the $M$ stations $\left(i=1\right.$ to $M$ ), the cepstrum $C_{i}(t)$ is a function of time delay between the direct $P$ wave and reflected waves in the P-coda.

Cepstrum peaks ( $C_{\mathrm{i}}$ maxima) are mainly due to P-pP, P-sP and P-PcP interactions (Letort et al. 2015). P-PcP interactions do not bring useful information on focal depth and could even bias depth estimation if P-PcP delays are wrongly interpreted as P-pP delays. Thus, using the ak135 velocity model (Kennett et al. 1995), theoretical P-PcP delays ( $\left.t_{i \_ \text {PCP-P_th_0-700 } \mathrm{km}}\right)$ are estimated for a wide range of focal depths $(0-700 \mathrm{~km})$. Parts of the cepstra that could be related to $\mathrm{P}-\mathrm{PcP}$ interactions are simply put to 0 , such as:

$C_{i}\left(t_{i_{-} \text {PCP-P_-th_- } 0-700 \mathrm{~km}}\right)=0$

Then, we assume that the $C_{i}(t)$ values indicate a reflected phase arrival (at the time delay $t$ between the $P$ wave and the reflected wave) when they are above a certain level. This level is empirically chosen at 0.15 times above the value of the norm of $C_{i}$ (see example of Cepstral function in Fig. 2b). New Cepstral functions $C n_{i}(t)$ are then defined; null everywhere, except for the time delays between $P$ and the reflected phases, such as:

$\mathrm{Cn}_{\mathrm{i}}(\mathrm{t})=1$, if $\mathrm{C}_{\mathrm{i}}(\mathrm{t})>0.15^{*}\left|\mathrm{C}_{\mathrm{i}}\right|=0$ otherwise

At teleseismic distance, P-pP delays (resp. P-sP delays) depend only on depth estimation and velocity model. $T$ he $\mathrm{Cn}_{\mathrm{i}}$ cepstra are first assumed to be due to P-pP delays, they can hence be converted into an equivalent depth probability function $\left(d_{\mathrm{pP}_{\mathrm{i}}}\right)$ using the ak135 velocity model. They are then also converted into another equivalent depth probability function $\left(d_{-\mathrm{SP}-\mathrm{i}}\right)$ assuming this time they are due to P-sP delays.

The final depth probability function is simply the sum of all depth-converted cepstra (Fig. 2):

$d=\sum_{i=1}^{M}\left(d_{p P i}+d_{s P i}\right)$

\subsection{Validation of the Cepstral approach and comparison with ISC-EHB L1 events and extraction of depth resolution criteria}

We then compare depth localisation between Cepstral method and location from the ISC-EHB catalogue, for L1-events. To be sure that an event depth is well constrained by Cepstral estimation, the 


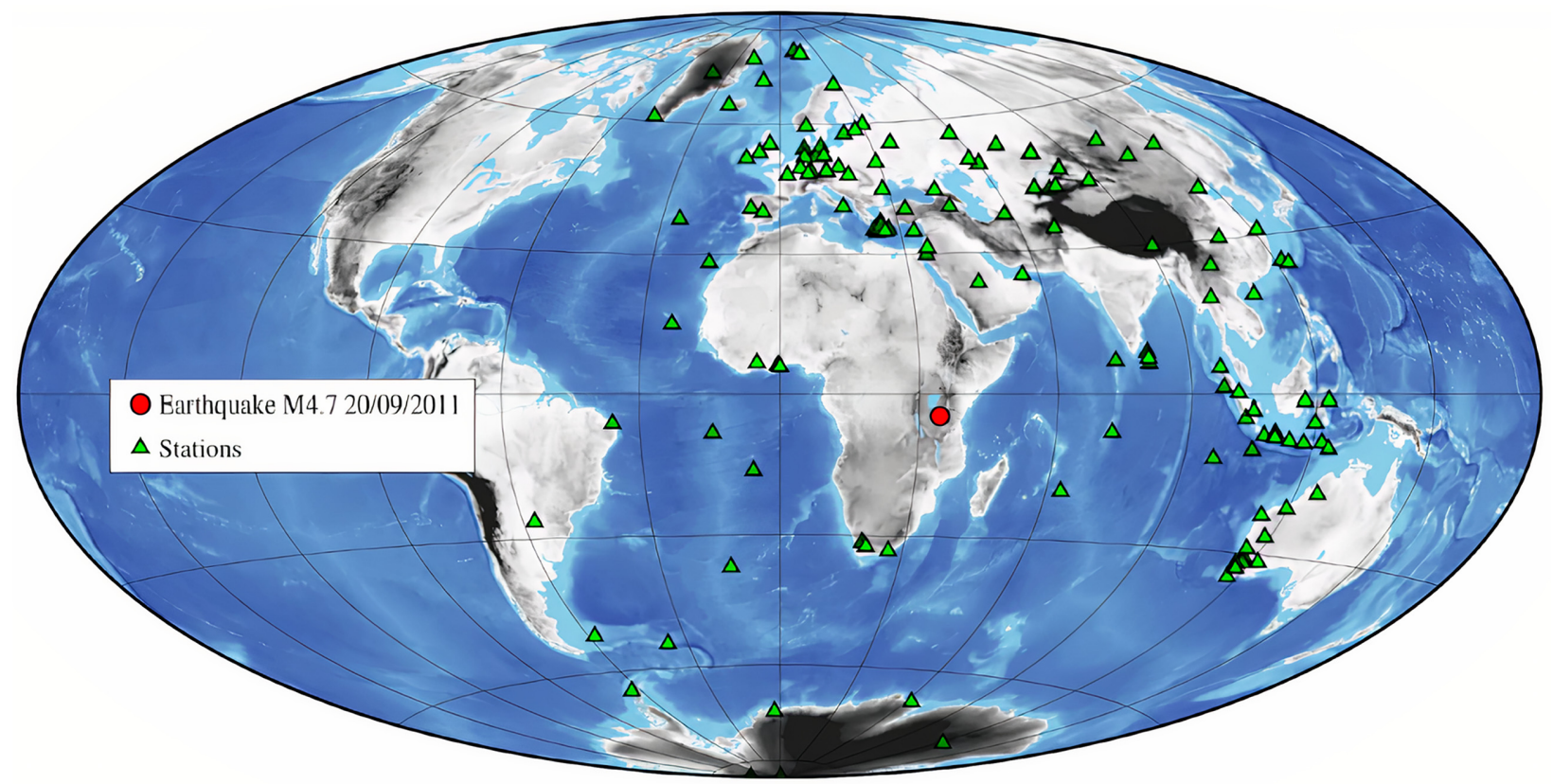

Figure 1. Teleseismic stations with clear depth phase detections identified from Cepstral analysis for the Tanzania earthquake, with magnitude 4.7, on 20 September 2011.

(a)

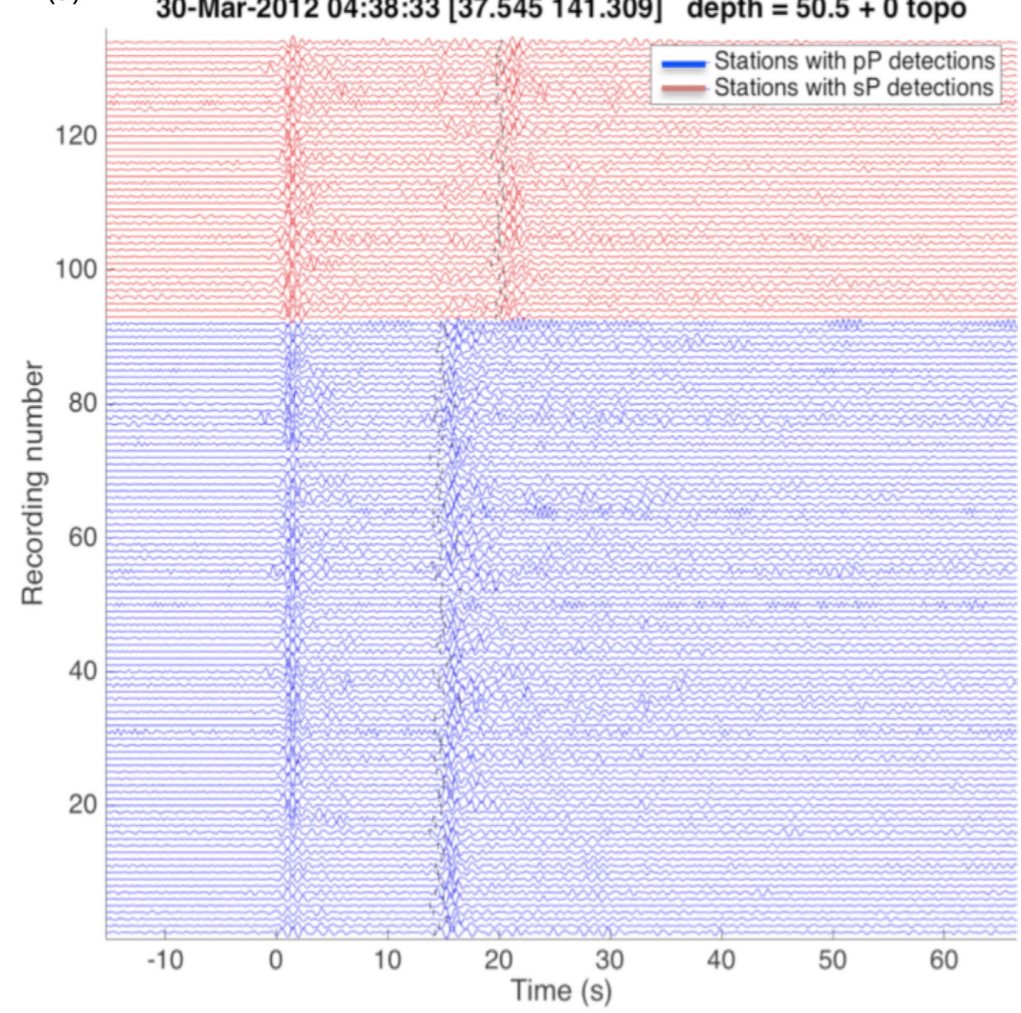

(b)

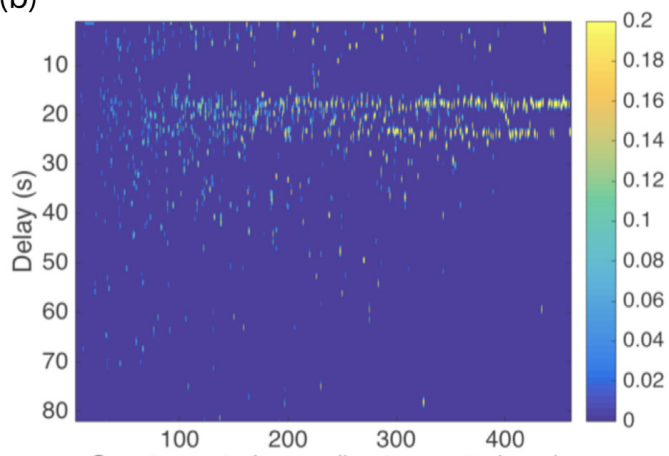

Cepstra sorted according to cepstral peak

(c)

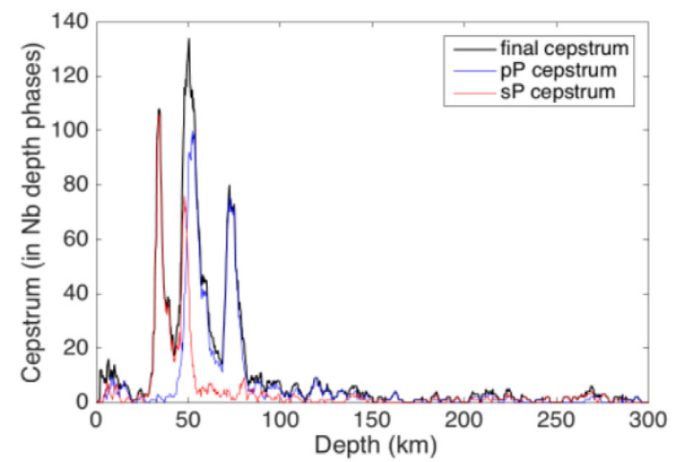

Figure 2. (a) All teleseismic recordings for one event (2012.03.30-04:38), re-aligned on the direct $P$-wave arrival (at $0 \mathrm{~s}$ ), where $\mathrm{pP}$ and sP arrivals have been detected automatically with SNR $>2$ and with a Cepstral peak $>0.15$. (b) Cepstra for all investigated recordings. (c) Final cepstra assuming pP detections only (blue), sP detections (red) and the combination of both kind of detections (black).

final depth probability function $d$ (eq. 3) gives a first interesting clue of the number of coherent detected depth phases, but it is not a sufficient criterion. The azimuthal coverage of the detections and the uniqueness of a main Cepstral peaks are two others strong clues of the success of the method.
Criteria for depth resolution have then been defined as follows:

An event is assumed to have constrained depth estimation if, and only if all the following conditions are respected:

(i) More than 20 coherent depth phases are detected. 
(ii) These depth phases have an azimuthal gap lower than $290^{\circ}$.

(iii) The maximum of the final depth probability function $d$ has to reach 10 times the value of its median (meaning $d$ shows a strong dominant peaks). The resolution threshold is then defined as $\operatorname{median}(d) / \max (d)<0.1$.

The first criterion is straightforward: the number of $\mathrm{pP} / \mathrm{sP}$ detected phases. The second criterion, based on the azimuthal coverage is introduced to give more confidence to the depth phase detections, to assure that coherent secondary arrivals are well observed on a large azimuthal range. A last, introducing the criterion on the value of the final depth probability function, allow to keep only events where the final Cepstrum function show a strong dominant peak. It allows to take account possible non-coherent detections which are not depth phases (reflected waves on 3-D structures, due to the propagation.). Hence, if the detected secondary phases are not coherently pointing to same depth estimation the final Cepstrum function will not have a strong peak. Then, even if a high number of secondary phases are detected in a wide range of azimuth, we will not retain this event as well constrained. To validate these criteria and choose the thresholds (20 phases - gap 290-C < 0.1), we have empirically tested different configurations of these criteria, until finding the combination that better satisfy the L1-ISC-EHB depth estimations (assumed to be the reference depth). With these three resolution criteria, 231 events from the 497 investigated events are assumed to be well constrained.

These Cepstral depth estimations are compared with the EHBL1 depth estimations: it shows a very small average difference $(0.6 \mathrm{~km})$ with a standard deviation of $8.5 \mathrm{~km}$ (Fig. 3a). This remaining quite large standard deviation is controlled by few deep events with important depth variations according to the two methods (Fig. 3b). These events have strongly coherent phase detections, but these phases are interpreted differently in terms of $\mathrm{pP} / \mathrm{sP}$, without any clues to know which solution is the best. This illustrates the burning issue of the $\mathrm{pP} / \mathrm{sP}$ interpretation, for all teleseismic approaches, which can lead to consequent bias in the depth estimations. However, note that for shallower crustal events, the difference between depth estimation derived from $\mathrm{pP}$ and $\mathrm{sP}$ became smaller. Hence, for the East-African Rift target, even with a misinterpretation of $\mathrm{pP} / \mathrm{sP}$ depth phase arrival, the approach should be able to distinguish an event at a depth of 10-12 km from another at $15-18 \mathrm{~km}$.

For this study, we rely on an unique 1-D velocity model (ak135). The choice of this approach is driven by (1) a lack of knowledge about exhaustive and more complex velocity models covering the whole area, (2) to keep a coherent depth estimation that could be compared with other teleseismic studies (Craig et al. 2011, ISCEHB-L1 catalogue) and (3) to provide an homogeneous catalogue for the area. When available, using local velocity models instead would improve the depth estimation as shown by Jerkins et al. (2020) and Gibbons et al. (2016). Letort et al. (2014), have also showed that a depth difference of $3-5 \mathrm{~km}$ could arise when using different models extracted the CRUST2.0 (Bassin et al. 2000) instead of using ak135 velocity model. Notes that uncertainties coming from the velocity model in the mantle and on the crust below the focal depth, are less important, as $P$ and $\mathrm{pP}$ follow approximately the same path and will be affected in the same way by a local velocity anomaly. But, the presence of shallow low-velocity sediment layers could affect greatly the depth estimation. The knowledge of the crustal structure above the source remains a key point to constrain the depth.

For the update of the seismic hazard estimation for the East African Rift, the goal is to be able to sort one event into one of the 4 depth range groups $(0-10 \mathrm{~km}, 10-20 \mathrm{~km}, 20-30 \mathrm{~km}, 30-$ $40 \mathrm{~km}$, see part 3.5). The use of a global 1-D velocity model such as ak135 should allow a reasonable sort into these 4 groups, even with large uncertainties of few kilometres. However we expect higher uncertainties for events in the Mozambique Channel: the difference of $\mathrm{pP}$ traveltime predictions between the ak135 velocity model and a more realistic local velocity model can be important in such an offshore context, as seen by Jerkins et al. (2020) for shallow North Sea events. We will discuss in part 3.4, this issue of depth estimation on this area.

Note also that well constrained events are seen for almost all locations on earth (Fig. 3c). No systematic bias according to earthquake location have been noted, which gives confidence on the success of the application for the East-African Rift System, that will be described now.

\section{DEPTH ESTIMATION FOR THE EAST-AFRICAN RIFT EARTHQUAKES}

\subsection{Data and selected events}

The 9575 East African Rift System events, reported in the ISC catalogue (International Seismological Centre 2020a), between 1st January 2005 and 1st January 2019, are all used. The exact same Cepstral analysis described in the previous paragraph is applied for depth estimation, on the teleseismic short-period data from the FDSN web service. The only change is a decrease of the time window length ( $80 \mathrm{~s}$ instead of $100 \mathrm{~s}$ ), as we expect to have only earthquakes with focal depth largely smaller than $100 \mathrm{~km}$ and it is not worth keeping a long time window. The same resolution criteria are applied, except for the number of detected depth phases, which has been relaxed to 10 arrivals because of a more restricted depth range and tectonic context, a more stable azimuthal coverage and a more stable number of scanned stations on the study area. Moreover, a manual check of the data is systematically processed, allowing us to reject few false detections due to multiple arrivals from regional events that mask the teleseismic arrivals. Finally, 584 earthquakes have assumed constrained depth estimation with magnitude generally above 4 , and even 14 events reaching weaker magnitudes, around 3.5 (these magnitudes have to be taken with care, as they have been extracted from the ISC (International Seismological Centre 2020a) website, mixing different kind of magnitude, $M_{\mathrm{L}}, m_{\mathrm{b}}, M_{\mathrm{s}}$ and even $M_{\mathrm{d}}$ ).

To ensure building the most exhaustive catalogue of constrained depth estimation for seismic hazard analysis, teleseismic depth estimations coming from published studies are used:

(i) 71 depth estimations from Craig et al. (2011) between 2005 and 2010 in our area.

(ii) 68 from the L1-ISC-EHB catalogue, that is events of the ISC-EHB catalogue with the L1 quality criterion, that ensures the highest constraint on depth estimation (Weston et al. 2018).

(iii) 189 from the pP-ISC catalogue, that is events of the ISC bulletin (International Seismological Centre 2020a) for which a 'pP-depth' parameter is available. This pP-depth is computed from the depth-phase stacking method introduced by Murphy \& Barker (2006) and detailed in Bondár \& Storchak (2011).

Events can have depth estimation with several of this three teleseismic methods, as well as with the Cepstral analysis. A total of 82 events have been estimated both from Cepstral analysis and at least one these teleseismic approach, which will provide some 
(a)

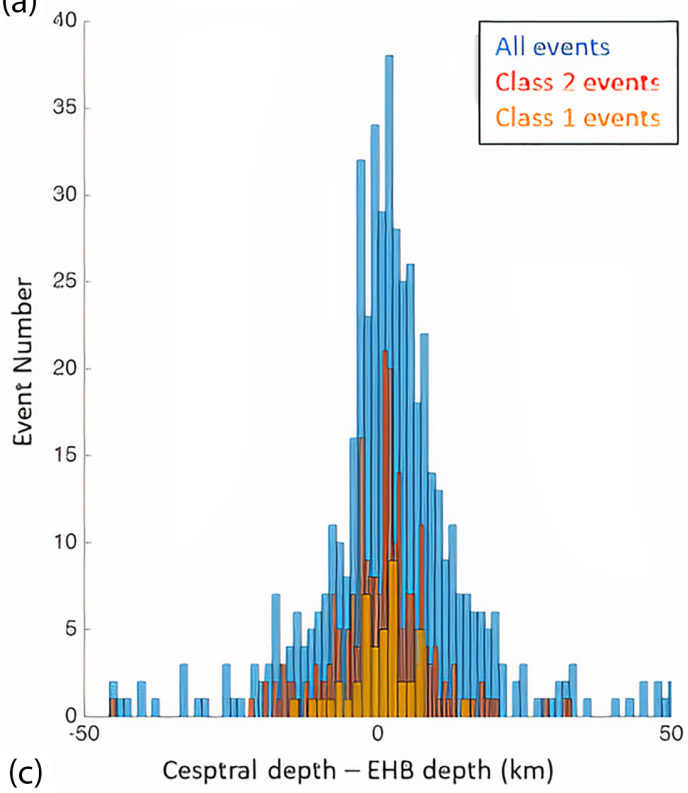

(b)

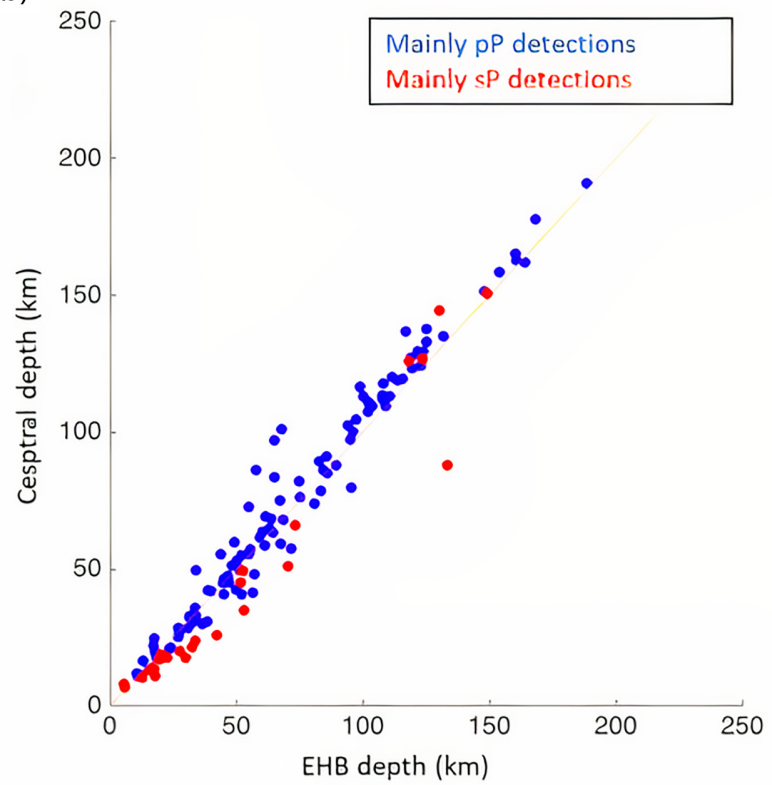

Table 1. Resolution criteria used to select seismic events with well constrained depth estimation from catalogue (Min.) Minimum.

\begin{tabular}{lc}
\hline Reference of the criteria & Criteria \\
\hline $\begin{array}{l}\text { Theunissen } \text { et al. } \text { (2018) } \\
\text { Letort } \text { et al. } \text { (2016) }\end{array}$ & Min. 1 station $<15 \mathrm{~km}$ and Azimutal gap $<180^{\circ}$ \\
This study & Min. 1 station $<50 \mathrm{~km}$ and $6 \mathrm{P} / \mathrm{S}$ phase pairs and Azimutal gap $<300^{\circ}$ \\
(Min. 1 station $<30 \mathrm{~km}$ and $4 \mathrm{P} / \mathrm{S}$ phase pairs)
\end{tabular}



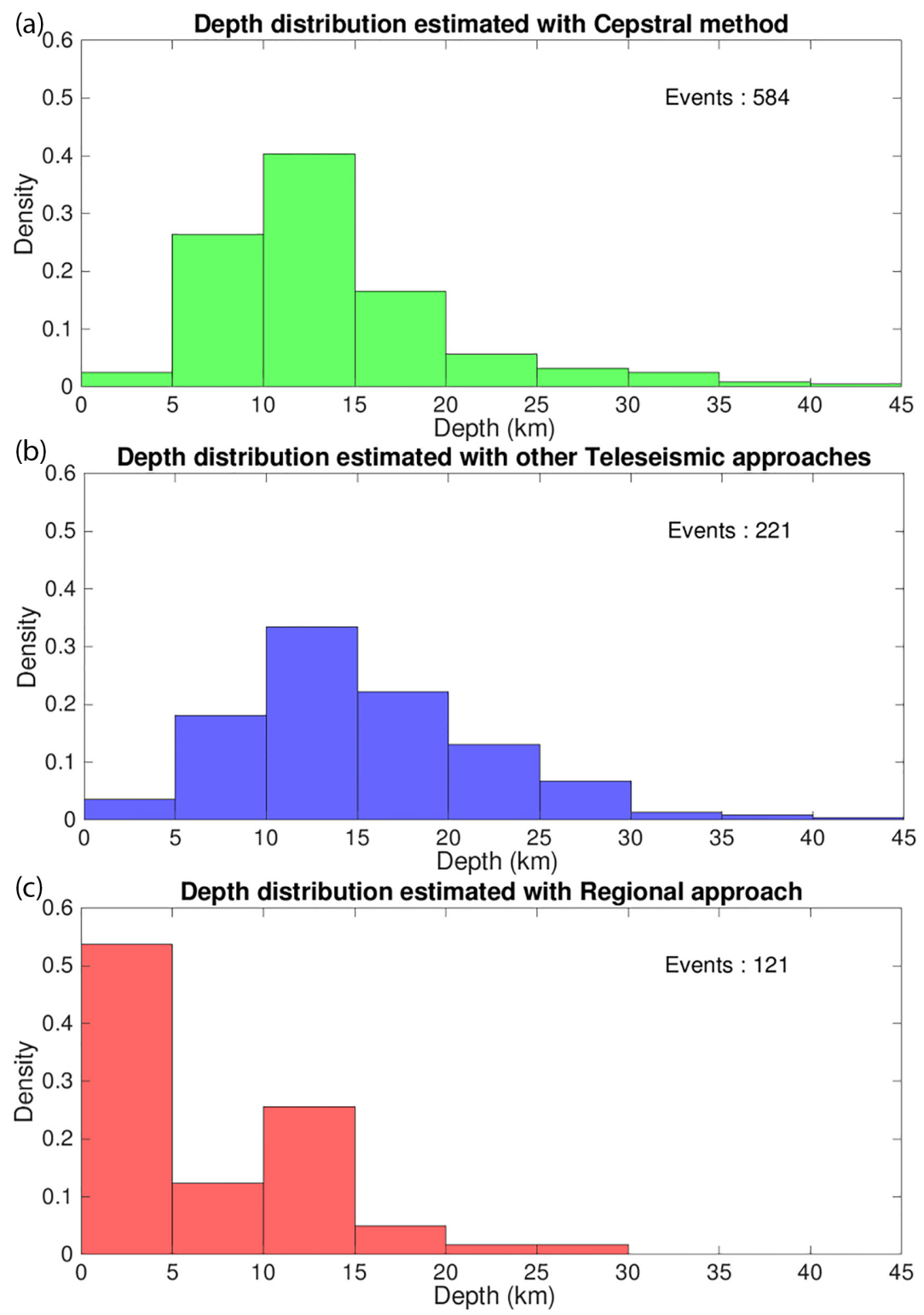

Figure 4. Depth distribution estimated with different approaches for the Eastern African Rift System: (a) Cepstral method, (b) other teleseismic approaches (Craig, pP-ISC and L1-ISC-EHB) and (c) regional network geometry criteria.

insight on depth estimation uncertainty and on the best approaches to constrain the depth estimation (see later, paragraph II.3). Moreover, 139 events were depth constrained by at least one of these teleseismic method, and were not in the previous catalogue obtained by Cepstral analysis. They were added to the list to obtain a catalogue of depth constrained event containing 723 events.

\subsection{Limitation of teleseismic depth estimation for shallow events: adding events constrained by regional data}

These previous teleseismic approaches (Cepstral analysis and the other three teleseismic depth estimation) all use teleseismic data and could thus be limited for shallow event depth estimation $(<5 \mathrm{~km})$ because the time delay between $P$ waves and depth phases is too short to be detected automatically (less than 2-3 s). A teleseismic catalogue could thus be biased, lacking shallower events, which would play a huge role on seismic hazard characterisation. In order to deal with this burning issue, an exhaustive study of depth resolution from regional localisations has been carried out, allowing us to extract from the ISC bulletin 121 seismic events assumed to be well constrained at depth, as explained below. Among them, 8 were already in the previous list, which allowed comparisons with other methods and 113 events were not in the previous list, and were added to it to obtain a final catalogue of 836 events. The ISC bulletin has been scanned and events with supposedly reliable depth estimation have been selected according to empirical criteria based on the number, the kind $(P, S)$ and the repartition (distance, azimuth) of the phases used for the localisation procedure. Indeed, several authors have proposed that the network geometry can control the quality of the depth estimation (Bondár \& Storchak 2011; Letort et al. 2016; Theunissen et al. 2018). Here, three different sets of criteria are used (Table 1) to extract events with constrained regional depth estimations. For each event fulfilling one of these three criteria, we used the depth indicated by the prime location of the ISC bulletin 
(a) Comparison between Cepstral events depth and Teleseismic events depth

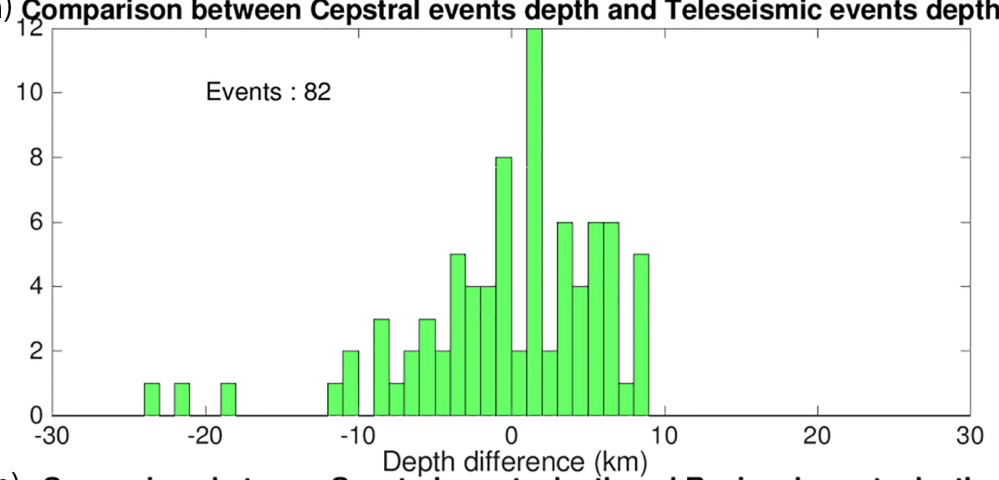

(b) Comparison between Cepstral events depth and Regional events depth

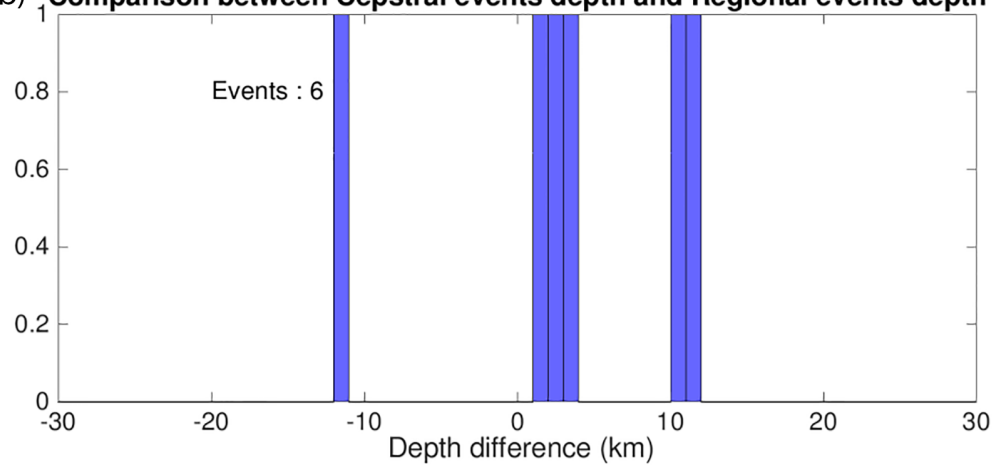

Figure 5. Difference of depth estimation between Cepstral method and (a) other Teleseismic approaches and (b) Regional approach.

Table 2. Difference in depth estimation for events with multiple depth estimates compared to the depth estimated with the Cepstral method. Craig et al. (2011) (A): full waveform inversion method. Craig et al. (2011) (B): P-depth phases delay.

\begin{tabular}{|c|c|c|c|c|c|c|c|}
\hline Approaches & $\begin{array}{c}\text { pP ISC } \\
\text { (teleseismic) }\end{array}$ & $\begin{array}{l}\text { L1-ISC-EHB } \\
\text { (teleseismic) }\end{array}$ & $\begin{array}{l}\text { Craig et al. (2011) } \\
\text { (A) (teleseismic) }\end{array}$ & $\begin{array}{l}\text { Craig et al. (2011) } \\
\text { (B) (teleseismic) }\end{array}$ & $\begin{array}{l}\text { Letort et al. (2016) } \\
\quad \text { (regional) }\end{array}$ & $\begin{array}{l}\text { Theunissen et al. } \\
\text { (2018) (regional) }\end{array}$ & $\begin{array}{l}\text { This Study } \\
\text { (regional) }\end{array}$ \\
\hline Number of events & 73 & 24 & 7 & 17 & 5 & 2 & 6 \\
\hline Mean (km) & -1.8 & 0.7 & 4.9 & 1.7 & 3.3 & -0.5 & 3.0 \\
\hline
\end{tabular}

(i.e. the most reliable location according to ISC analysts), except if this depth is indicated as a fixed depth, in which case the event is discarded.

To summarize, well-constrained events are selected by three different classes of approaches: (i) from the Cepstral analysis, (ii) from other published teleseismic approaches (Craig, pP-ISC and L1-ISC-EHB) and (iii) from regional bulletins and catalogues, and according to empirical network geometry criteria. The complete depth distributions for the Eastern African Rift System obtained from those three approaches are shown in Fig. 4. As expected, a clear difference is observed on the percentage of shallow events $(<5 \mathrm{~km})$, according to the teleseismic or regional datasets used. Teleseismic depth estimations are indeed not appropriate for shallow events. The deep-earthquake parts of the depth distributions $(>5 \mathrm{~km}$ ) look similar for the Cepstral method and for the other teleseismic approaches.

\subsection{Depth estimation uncertainties}

Combining the three methods provides different depth estimations for a same event, allowing for the evaluation of epistemic uncertainties in the depth estimation and identifying which approach/method should prevail to define the best focal depth estimation.
The comparison of the 82 events having both a Cepstral and another teleseismic depth estimation shows an important standard deviation of $6.4 \mathrm{~km}$ (Fig. 5a). It illustrates the significant remaining uncertainties in the final catalogue. Similar observations can be made comparing Cepstral and regional depth estimation (Fig. 5b) even if only 6 events are common, with an average difference of $3.1 \mathrm{~km}$ and standard deviation of $8.2 \mathrm{~km}$. Going into more detail, it appears that the Cepstral analysis presents the best agreement with the study of Craig et al. (2011) and with the L1-ISC-EHB catalogue (Table 2). It is on average in good agreement with L1-ISC-EHB, even with a still quite large standard deviation $(6.9 \mathrm{~km})$, and shows a small systematic shift $(1.7 \mathrm{~km})$ with the depth estimations of Craig et al. (2011) with a very small standard deviation $(3.8 \mathrm{~km})$.

These two kinds of methods are assumed to be the trust worthiest. The L1-ISC-EHB catalogue is assumed to contain events with focal depth well constrained at $5 \mathrm{~km}$ (Weston et al. 2018) and Craig et al. (2011) have conducted a specific and exhaustive study of depth estimation for African earthquakes, aiming to identify the best estimated focal depth. The consistency between Cepstral depth estimation and these two approaches is therefore an indication of the efficiency of the Cepstral depth estimation of these two catalogues. The pP ISC catalogue, estimated from the combination of manual 
pickings from different institutes, and without a systematic check of the depth phase's identifications, is assumed to be less constrained than the Cepstral, L1-ISC-EHB and Craig's catalogues.

Among the regional approaches, the resolution criteria proposed by Letort et al. (2016) and Theunissen et al. (2018) are more restrictive than the ones proposed in this study. The regional depth estimations are assumed to be less reliable than those obtained from teleseismic approaches. This hypothesis could be debated, but it allows to have a final catalogue with a majority of events constrained by teleseismic data for the whole area, keeping it homogeneous and less dependent on local network geometry (see next paragraph).

Under these hypotheses/observations, a ranking of depth estimation accuracy is proposed among all these approaches:

(1) The Cepstral depth estimation method.

(2) Craig et al. (2011) using its full waveform inversion method.

(3) Craig et al. (2011) from P-pP delays.

(4) The L1-ISC-EHB method.

(5) The pP ISC approach.

(6) From the regional location, if the Theunissen et al. (2018) resolution criteria are satisfied.

(7) From the regional location, if the Letort et al. (2016) resolution criteria are satisfied.

(8) From the regional location, if the 'Study' resolution criteria are satisfied.

For each of the 836 events of the catalogue, a unique depth estimation was selected: the one with the highest accuracy according to this ranking. This results in the definition of three subgroup in the catalogue: 584 events for which the final depth estimation were obtained by Cepstral analysis, 139 events for which it was obtained by teleseismic approaches and 113 for which the final depth has been obtained by regional approach.

\subsection{Final depth distribution of the East African Rift system: validation/comparison through consistency with regional tectonic features}

To assess the seismic hazard of the East African Rift, Poggi et al. (2017) defined six zones (Fig. 6a) having a common mechanical behaviour and a similar rheological profile. In the present study, the same zones will be used. The Fig. 6(b) shows the depth distribution of our 836 events of the final catalogue inside the 6 zones. We saw previously that the three classes of depth estimation methods (A. Cepstral, B. other teleseismic, C. regional) rely on different approaches and show different kinds of limitations. It is therefore interesting to note that they do not constrain the same earthquakes and/or areas (example for group 4 in Fig. 7). For instance, the regional approach allows for the identification of a family of shallow earthquakes for the group 4 (in green on Figs $7 \mathrm{c}$ and $\mathrm{f}$, right-hand panel). There lies one of the most active volcanoes in Africa, the Nyiragongo, close to Lake Kivu (Pouclet et al. 2016; Oth et al. 2017). However, this clustering of shallow earthquakes is not visible using the teleseismic approaches, which perfectly illustrates the complementarity of the different methods and the possible bias of teleseismic approaches in dealing with shallow events.

Since they do not depend on the spatial coverage of regional networks, teleseismic approaches logically cover a much larger area (Fig. 7). The Cepstral approach shows a clustering of the seismicity along a deep structure, not seen by the other approaches (Fig. 7d, blue). This seismicity is distributed along a fault system near Lake
Edward between the Democratic Republic of Congo and Uganda (Chorowicz 2005; Ebinger 1989; Skobelev et al. 2004; Craig et al. 2011). These coherent depth variations thus provide evidence of the efficiency of the Cepstral analysis for this area and, once again, the complementarity between all approaches, sensitive to different kind of structures/depth/areas.

Note a vertical alignment (pink on Figs $7 \mathrm{a}$ and $\mathrm{d}$ and Figs $7 \mathrm{~b}$ and e), which represents aftershocks of a magnitude 7 earthquake that occurred in Mozambique in February 2006 (Yang \& Chen 2008). Another concentration of earthquakes (in black, Figs 7a and d) is related to a seismic swarm in Malawi in December 2009 (Biggs et al. 2010).

The source zonation covers a part of the Mozambique Channel, between Africa and Madagascar island, where an open debate exists about the location of the crustal oceanic/continental transition zone (Leinweber et al. 2013; Franke et al. 2015; Klimke et al. 2018). As expected, no events can be constrained by regional networks in this oceanic context (Fig. 8). Significant differences are also observed between the different teleseismic approaches (Figs 8a and b). Especially, some events are located deep in the mantle by the non-Cepstral approaches, when taking as reference the Moho depth (around $16 \mathrm{~km}$ ) from the CRUST 1.0 model (Laske et al. 2013). This deep seismicity could imply the presence of mantle seismicity or an indication of a Moho discontinuity deeper than reported.

This observed large depth variation can also be explained by a different interpretation of the detected depth phases: pwP phases (phases reflected on the top of the water layer) are preferentially chosen instead of pP arrivals by the Cepstral approach in oceanic context when the water column is greater than $1500 \mathrm{~m}$. This results in event depths shallower than under the assumption of $\mathrm{pP}$ arrivals (see for instance Letort et al. 2014). Discrimination between $\mathrm{pP} / \mathrm{pwP}$ arrivals is challenging, which gives three possible scenarios:

(1) Deeper events in the Mozambique Channel do exist, which could imply that the crust is thicker than reported in CRUST1.0 for the central part of the Channel (around 15-20 km). This could hence support the hypothesis that the central Mozambique Channel is composed mainly of continental crust as proposed by Franke et al. (2015) and Lort et al. (1979). Alternatively, this deep seismicity could also be seated in the upper mantle.

(2) The events are all located between 5 and $20 \mathrm{~km}$ depth in the centre of the Channel, with pwP detections. Then, the seismicity is likely to be confined in the crust, above the Moho transition zone.

(3) Real velocities are in fact much lower than in ak135 model and thus our depth estimations are overestimated (Jerkins et al. 2020).

Teleseismic data could hence provide useful information by constraining the seismicity depth for such geographically remote areas. However, the uncertainty on the depth estimation remains large due to the $\mathrm{pP} / \mathrm{pwP}$ indeterminacy and choice of relevant velocity models. Resolving this indeterminacy would allow better understanding of the tectonic processes at work here.

\subsection{Final depth distribution for each source zone}

In the previous paragraphs, an exhaustive selection of the best depth estimations for the East-African Rift seismicity for the years 20052019 allows us to complete the previous catalogue provided by Craig et al. (2011) for the years 1964-2010. This catalogue is a mix of different approaches, dominated by teleseismic Cepstral 

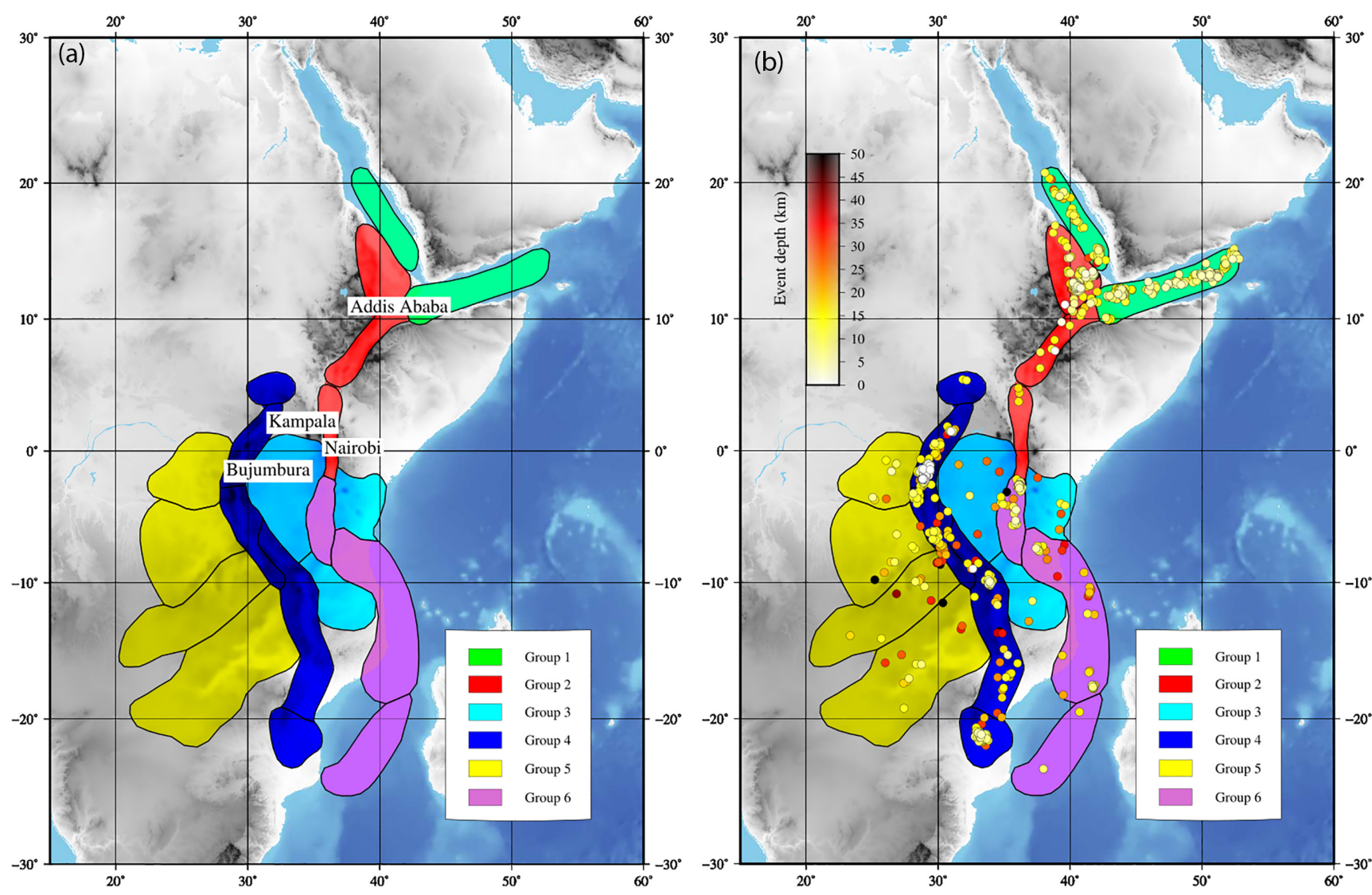

Figure 6. (a)Zonation of the Eastern Africa Rift System by Poggi et al. (2017). (b)Zonation of the Eastern Africa Rift System by Poggi et al. (2017) with our depth distribution of our final catalogue.

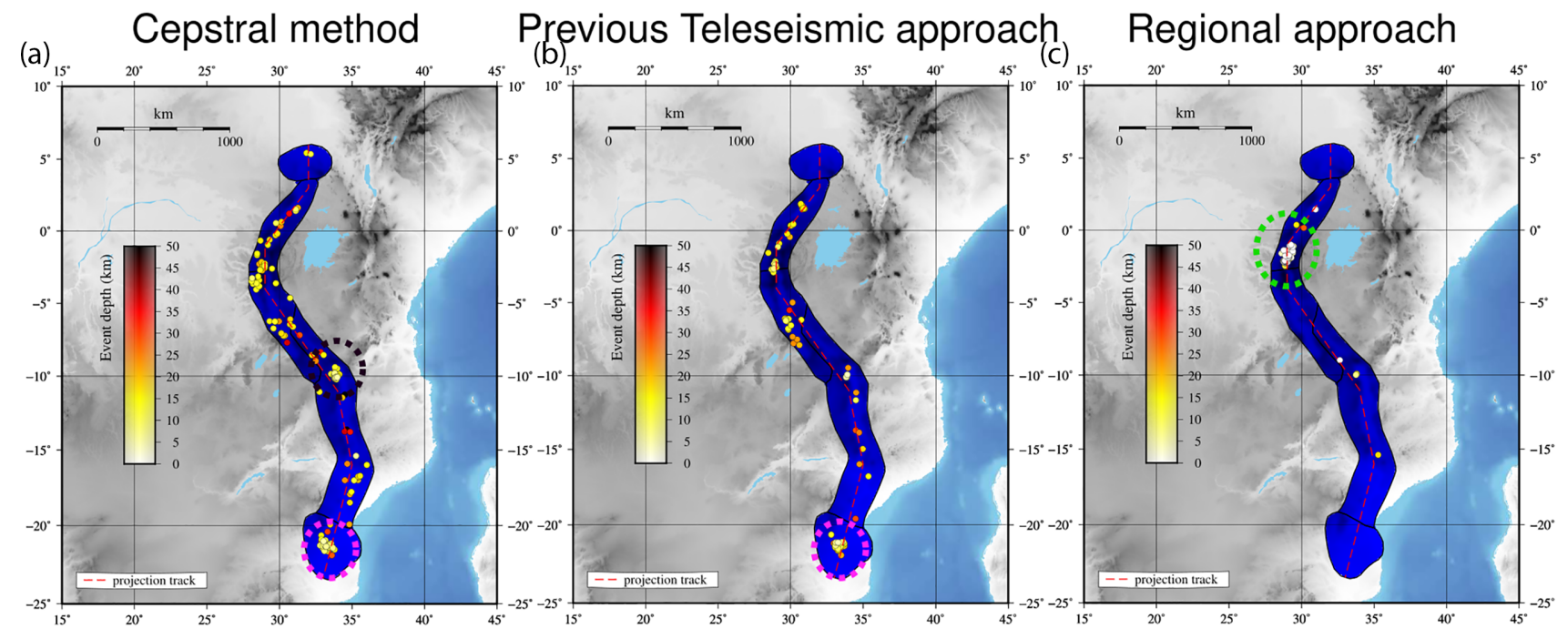

(d)

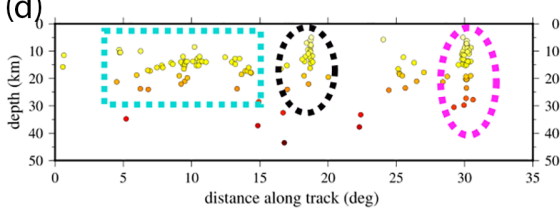

(e)

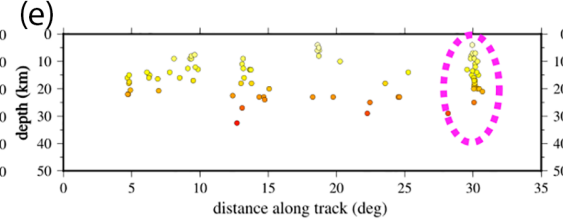

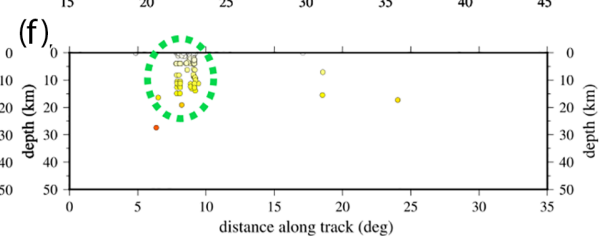

Figure 7. Maps and cross sections for depth estimation of Group 4 events. Colour represents the depth estimation. (a) Maps for depth estimate with Cepstral method. (b) Maps for depth estimate with other teleseismic approaches. (c) Maps for depth estimate with regional approach. (d) Cross section for depth estimate with Cepstral method. (e) Cross section for depth estimate with other teleseismic approaches. (f) Cross section for depth estimate with regional approach. 


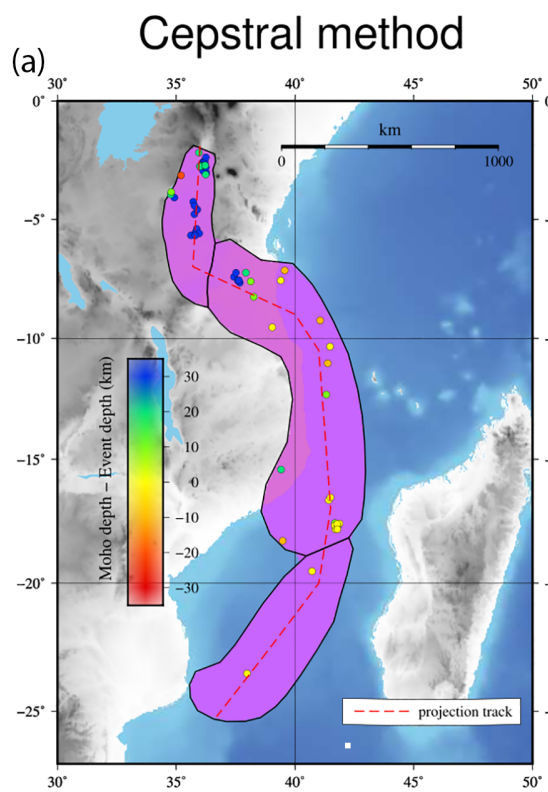

(d)

Previous Teleseismic approach Regional approach
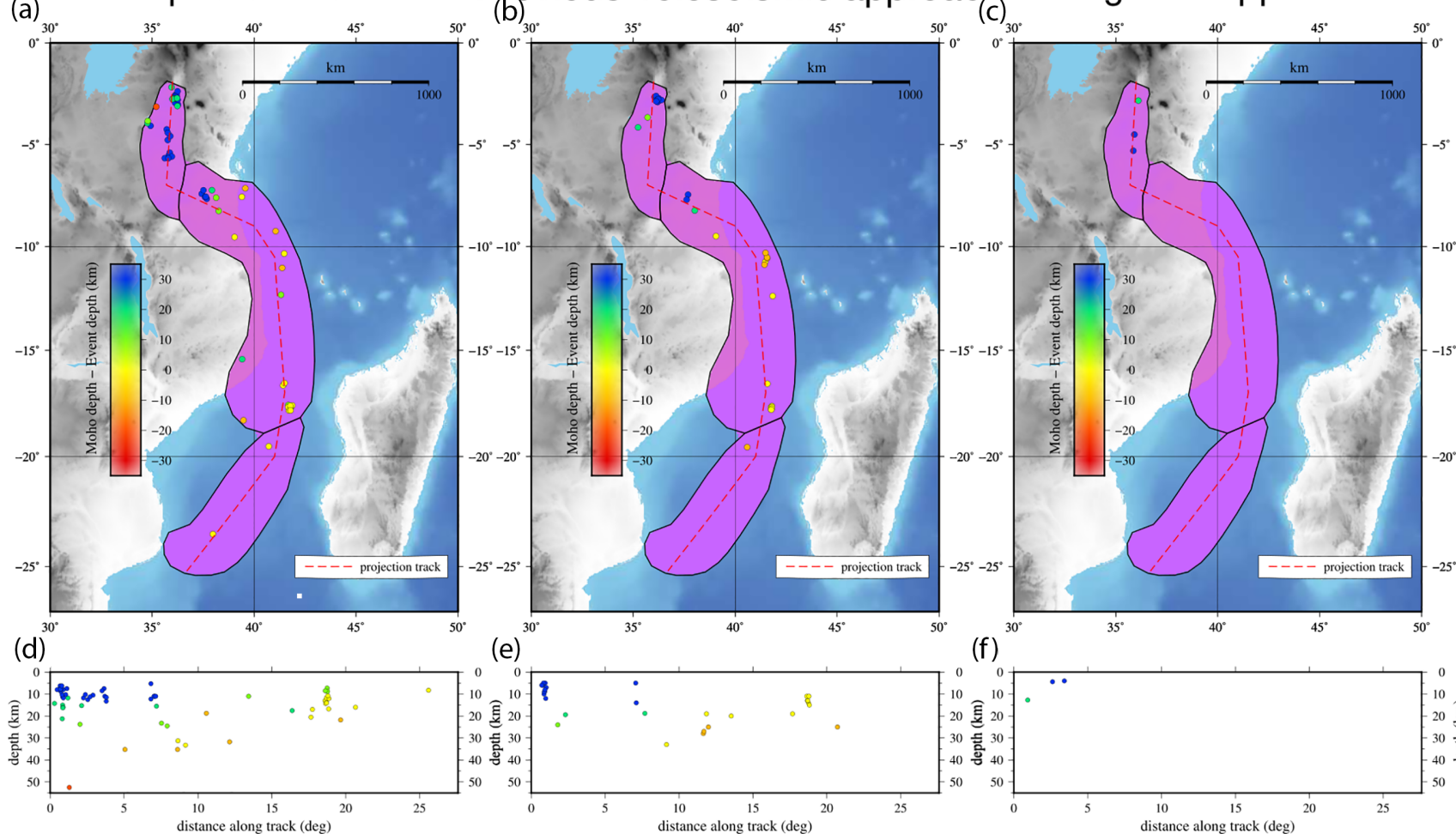

(e)

(f)
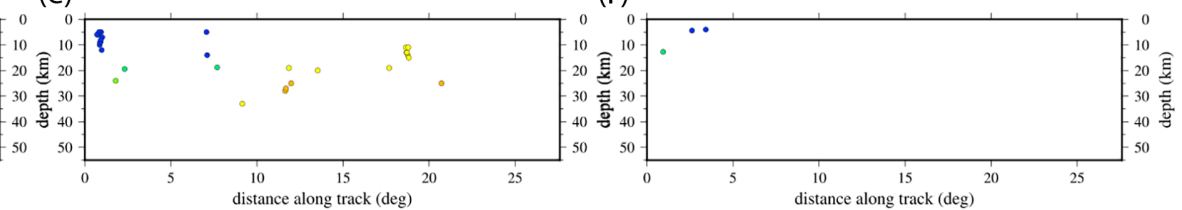

Figure 8. Maps and cross sections for depth estimation of Group 6 events. Colour scale represent the difference between depth estimation of Moho given by the CRUST 1.0 model and the depth estimated by Cepstral (a, d), Teleseismic (b, e) and Regional (c, f) approaches.
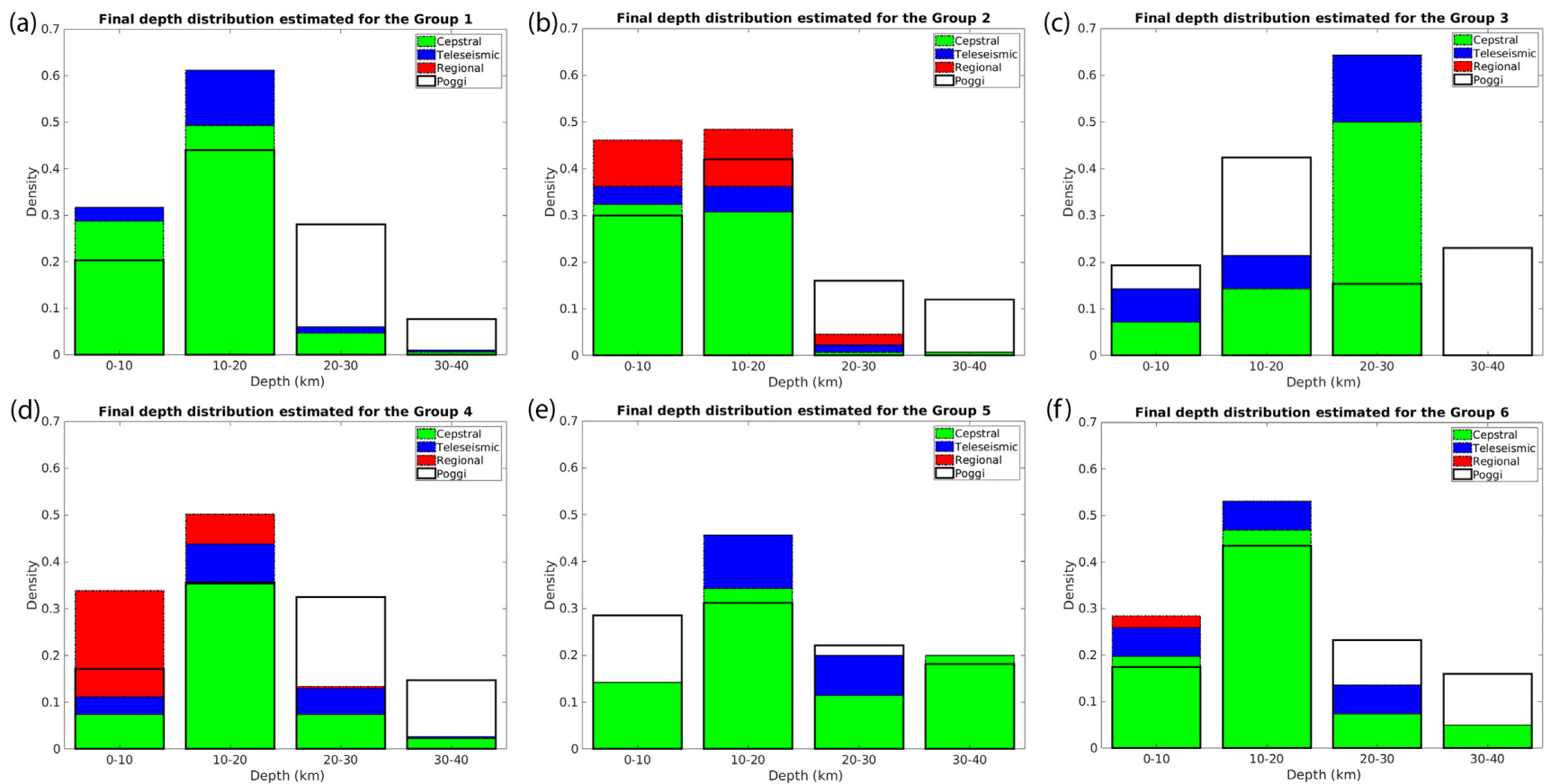

Figure 9. Final distribution of the estimated depth for the 6 groups, each colour corresponds to the proportion of events estimated with each approach (green: Cepstral approach, blue: Teleseismic approach, red: Regional approach). In white, delimited by the thick dark line the final distribution of the depth estimated by Poggi et al. (2017).

depth estimations. Despite the possible remaining depth uncertainties highlighted by the comparison between methods (see previous paragraph, 3.3), the consistency of earthquakes location with the tectonic features is a strong indication of the robustness of the final catalogue provided in supplementary material. This in turn allows us to define more precise source model for the six zones of Poggi et al. (2017) and to refine the seismic hazard assessment. Final depth distributions are significantly different from those proposed 


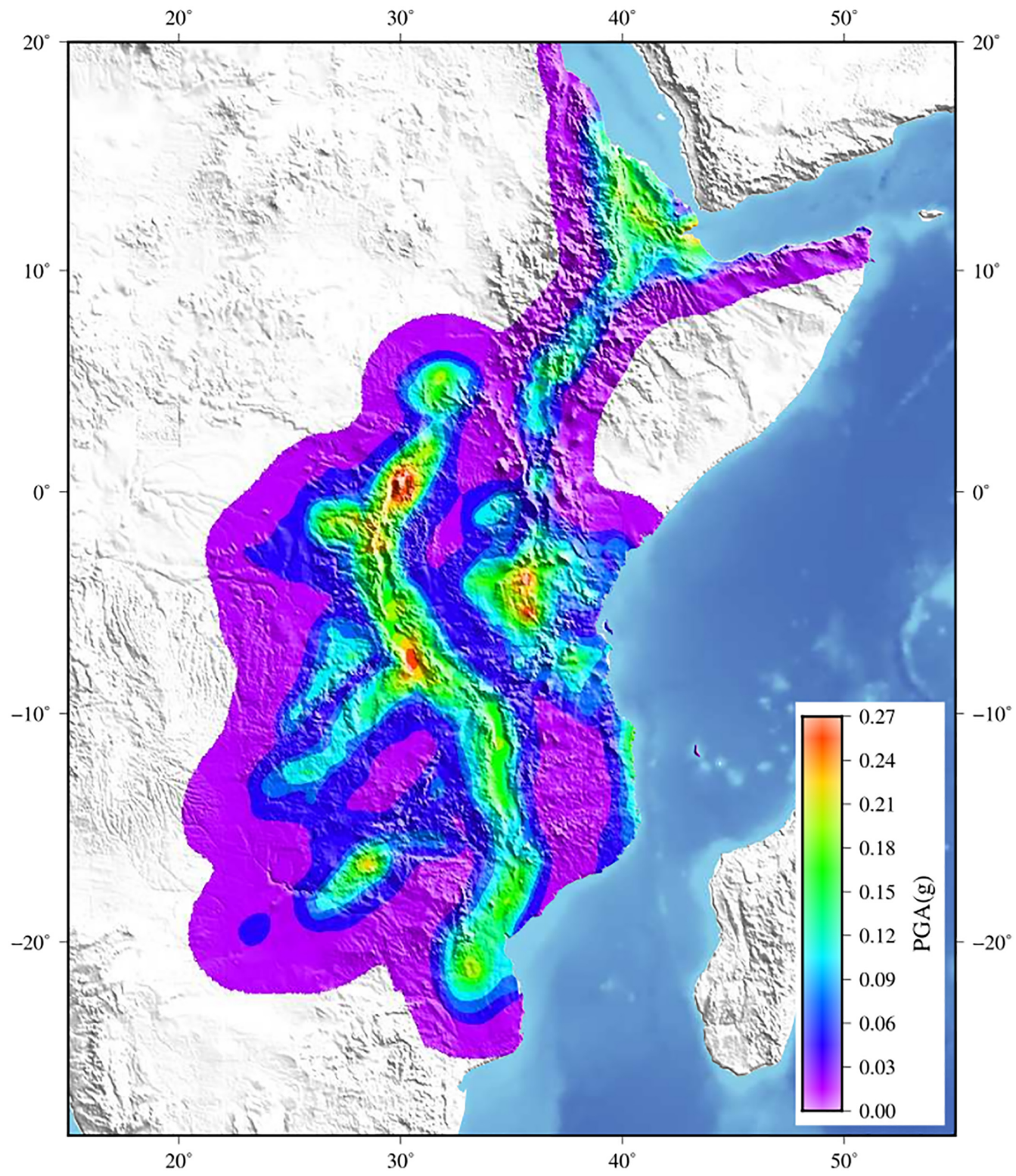

Figure 10. Maps of seismic hazard obtained with new depth estimation. g: acceleration due to gravity. PGA: peak ground acceleration for a 10 per cent probability of exceedance in $50 \mathrm{yr}$.

by Poggi et al. (2017) (Fig. 9). The depth distribution differences are especially important for the proportion of shallow $(<5 \mathrm{~km})$ versus deeper events (except for groups 3 and 5). Group 3 shows a higher proportion of deeper events $(>20 \mathrm{~km})$, consistently with intraplate tectonic context, with thicker crustal structures.

Despite different depth constraints and different sources of uncertainties, the depth distributions deeper than $5 \mathrm{~km}$ show the same pattern for the three approaches (Fig. 4). This gives great confidence on the picture of the seismicity distribution in this depth range in the Eastern Africa Rift System. The shallower part of the distribution $(<5 \mathrm{~km})$ is different according to the chosen approach, is mainly constrained by events estimated through the regional approach (113 events) and could thus be a biased version of the real seismicity distribution. Favouring the teleseismic approaches could lead to an underestimation of the number of shallow events. Thus, the higher proportion of shallower events observed for 4 groups compared to Poggi et al. (2017) could be more drastic.

\section{IMPLICATION OF NEW DEPTH DISTRIBUTIONS FOR SEISMIC HAZARD ASSESSMENT}

We re-evaluated the East-African Rift seismic hazard, through the use of Openquake (Global Earthquake Model, GEM) computational tools. OpenQuake software uses a logic tree implementation, with 4 GMPEs (ground motion prediction equations) and different source models. We have taken exactly the same source model and ground motion logic tree configuration as used by Poggi et al. (2017), except for the source depth distributions, which are now defined from the new improved depth catalogue (Fig. 9). The resulting PGA (peak ground acceleration) for a 10 per cent probability of exceedance in $50 \mathrm{yr}$, using a mesh of 79109 sites spaced at approximately $10 \mathrm{~km}$ (see Poggi et al. 2017) is shown in Fig. 10. Largest accelerations $(0.21-0.27 \mathrm{~g})$ are found close to Lake Kivu (Group 4) near several active volcanoes like Nyiragongo volcano, and in the Eastern Rift 

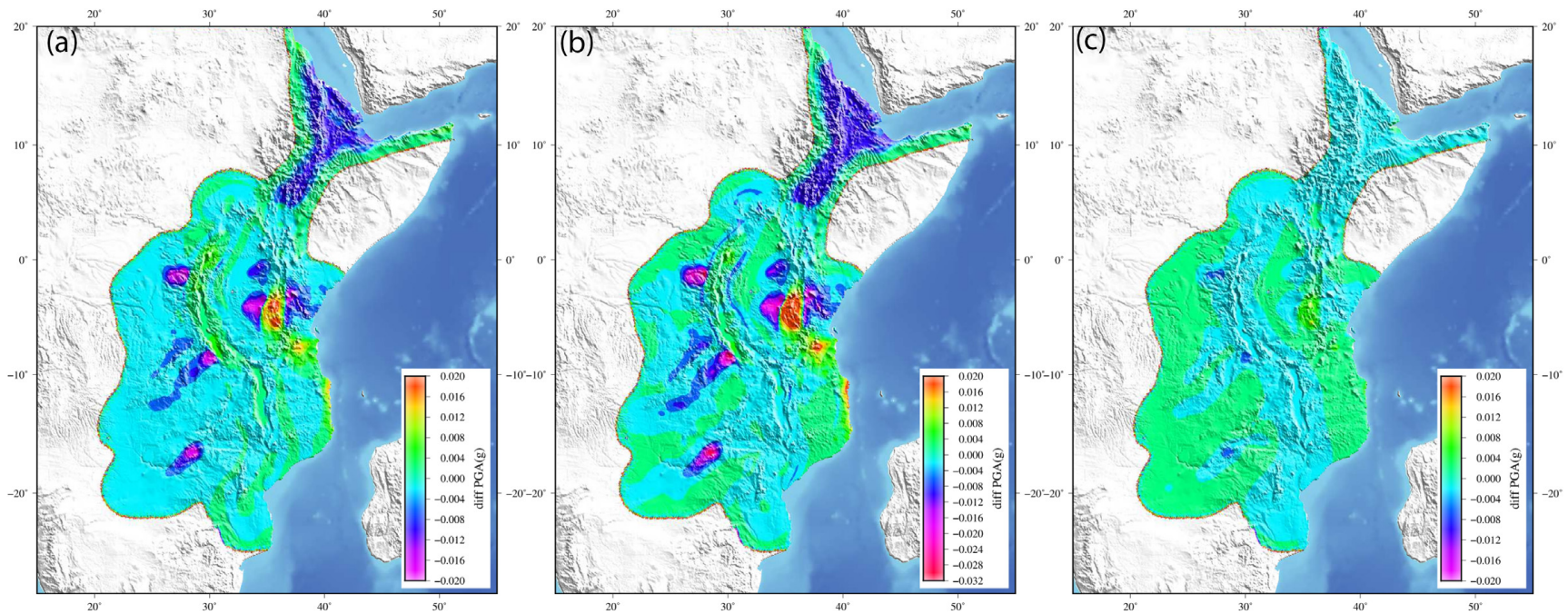

Figure 11. Difference of PGA between: (a) Our new depth distribution and Poggi et al. (2017). (b) Our new depth distribution without regional approach and Poggi et al. (2017). (c) Our new depth distribution and our new depth distribution without events constrained by the regional approach.

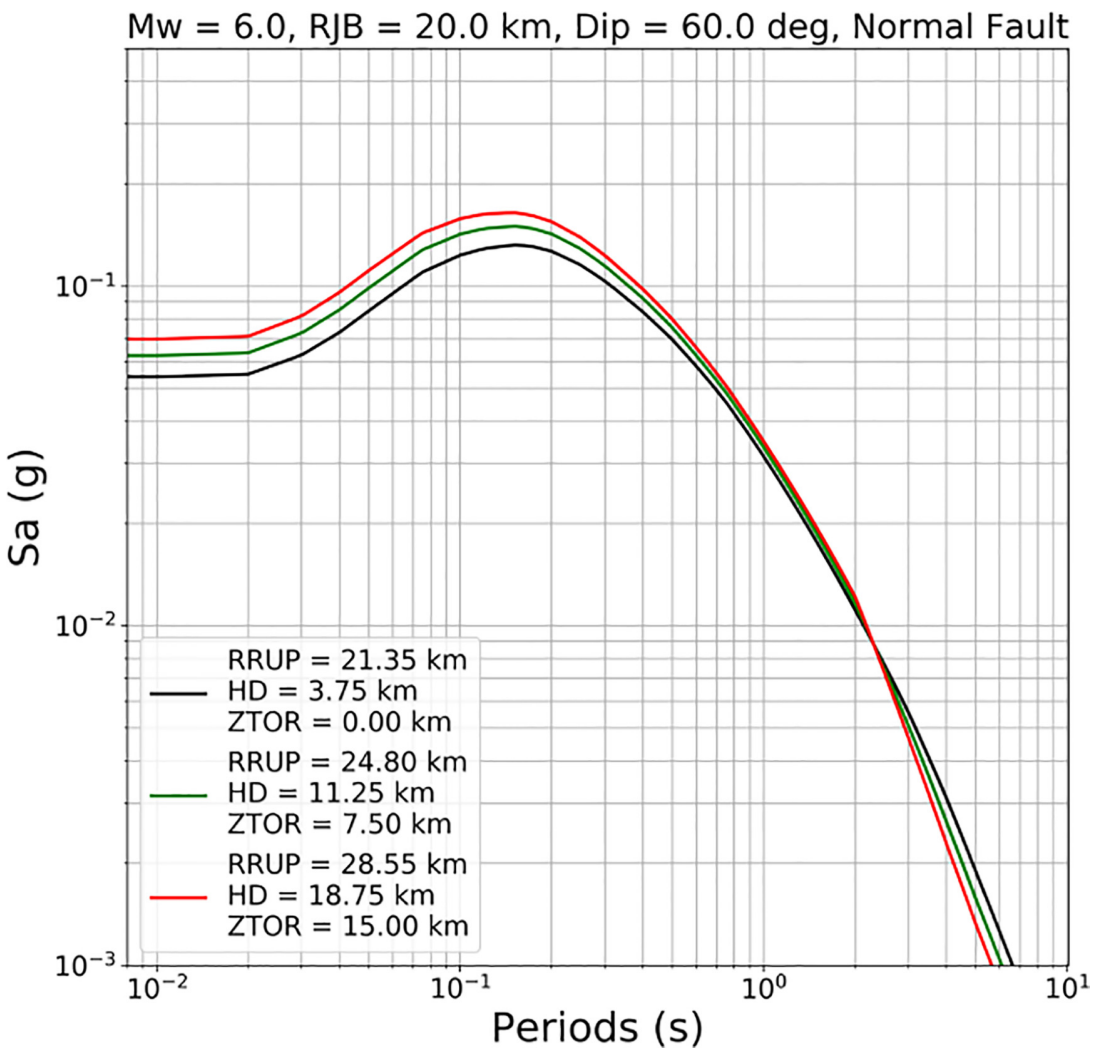

Figure 12. Response spectra from CY14 for three earthquakes that have the same epicentral distance $(20 \mathrm{~km})$, the same magnitude from a same site and with three different depths $(3.75 \mathrm{~km}, 11.25 \mathrm{~km}, 18.75 \mathrm{~km})$. The acceleration spectrum (close to PGA) for the deeper event, in red, is higher for small periods than for the shallowest (in black).

System (Group 6). Moderate PGA values (0.15-0.21) are found in the region of the Afar triple point.

Introducing the new depth distributions lead to an increase of the PGA values for some areas of the group 6 and a decrease for the groups 3 and 5 (see Figs 11a and 6). These local variations can be easily explained by the increase of the proportion of shallow events $(<10 \mathrm{~km})$ for group 6 and by a decrease of shallow events for groups 3 and 5 . Indeed, the sources are associated mostly with GMPEs that are dependent on distance to the rupture. This means that when the seismicity gets shallower the hazard increases as the net source-to-site distance is reduced.

For the group 2, the observed trend could seem counter intuitive: the source depths are shallower, however the hazard decreases. This decrease can be explained by the predominant role of the Chiou \& Youngs (2014) [CY14] GMPE in the logic tree for this area. This particular GMPE has a rupture depth scaling term that produces an increase in short-period acceleration for deeper events. This increase in PGA due to the higher stress drop from the deep events will be 
more important than the decrease in PGA due to the increase in source-to-site distance for deeper events (Fig. 12). Then, at close source to site distances, the deeper earthquakes actually produce higher ground shaking than the shallower ones.

This illustrates well the crucial importance of the choice of the GMPEs and how they take the source depth into account. The balance between the difference distance metrics and the possibility of depth-dependent short period ground motion increases predicted by the GMPEs, are what influence the change in hazard with source depth.

As adding the constrained focal depths coming from the regional approach tend to increase the proportion of shallow events in the distributions, we estimate also the seismic hazard removing those events (Fig. 11b), which bring only one major change in the PGA values: a clear decrease in the western Rift System for 2 volcanic areas (Fig. 11c).

Finally, the focal depth is taken into account indirectly in three of the GMPEs used by Poggi et al. (2017) by a modification of the distance to rupture parameter. Hence, the role of the depth distribution, proven to be non-negligible here, could even be underestimated in the final PGA values estimation.

\section{CONCLUSIONS AND DISCUSSIONS}

We constrained the teleseismic depth estimations of 584 events with magnitude mainly above 3.5 , completed by 139 reliable depth estimations from previous studies based on teleseismic data as well. We also identified from regional catalogues 113 earthquakes assumed to be well-constrained, based on network geometry empirical criteria.

Compiling different type of data (teleseismic and regional) and using several independent methods for depth estimation (Cepstral approach, use of manual teleseismic pP, sP picks, regional localizations), allows an estimation of the depth epistemic uncertainties. These uncertainties remain large, with standard deviation mostly around $7-8 \mathrm{~km}$ (Table 2). Cepstral depth estimations are shown to be coherent with both the L1-ISC-EHB catalogue and the Craig et al. (2011) catalogue, as well as with geologic and tectonic features.

The final depth catalogue is built after a drastic selection of constrained events and a sorting of the different depth candidates according to the different approaches, favouring the Cepstral depth estimation. It is hence composed of mainly teleseismic depth estimation and completed with few regional depth estimations, and assumed to be the most reliable and exhaustive catalogue suited for seismic hazard characterisation. The catalogue is assumed to be well representative of the earthquakes depth distributions of the different zones of the East-African Rift system, even if the exact proportion of shallows earthquakes $(<5 \mathrm{~km})$ is less constrained.

The use of teleseismic approach brings important information to better understand the seismicity on poorly instrumented areas, and especially for remote transition zones between continental and oceanic crust.

Finally, the use of OpenQuake with the new improved depth distributions highlights significant differences in the PGA values, up to 10 per cent, compared to Poggi et al. (2017). Even if the earthquake-resistant building standard would not be affected in this specific case, this study illustrates that source depth distribution could play a non-negligible role on the seismic hazard characterization. Indeed, a 10 per cent change of the PGA value is obtained after introducing a moderate change in the source depth distribution function. Moreover, this study shows the crucial importance of the choice of the GMPEs and how they are taking into account the effect of the source depths on the ground motions. This study pushes forward the interest of characterizing more precisely the depth parameter influence on seismic hazard studies including the focal depth as a direct GMPE parameter and/or studying more the relationship between stress drop and depth according to different tectonic features. More generally, this study motivates more exhaustive theoretical analyses of the role of the source depth distribution in the seismic hazard characterisation.

\section{ACKNOWLEDGEMENTS}

We would like to thank the reviewers István Bondár, Steven J. Gibbons and Raymond Durrheim for their constructive and thoughtful comments allowing to improve our manuscript. We also would like to thank the editor Gabi Laske, assistant editor Louise Alexander and the editorial team for their work on our manuscript.

\section{DATA AVAILABILITY STATEMENT}

The data underlying this paper are open data. The used bulletin is freely available at International Seismological Centre (2020a), On-line Bulletin, https://doi.org/10.31905/D808B830 and at International Seismological Centre (2020b), ISC-EHB dataset, https: //doi.org/10.31905/PY08W6S3.

The facilities of IRIS Data Services, and specifically the IRIS Data Management Center, were used for access to waveforms, related metadata, and/or derived products used in this study. IRIS Data Services are funded through the Seismological Facilities for the Advancement of Geoscience (SAGE) Award of the National Science Foundation under Cooperative Support Agreement EAR-1851048.

Catalogue of Craig, T.J., Jackson, J.A., Priestley, K. \& McKenzie, D. (2011) Earthquake distribution patterns in Africa: their relationship to variations in lithospheric and geological structure, and their rheological implications. Geophysical Journal International, 185, 403-434, doi:10.1111/j.1365-246X.2011.04950.x.

Codes are available on request to jean.letort@irap.omp.eu.

\section{REFERENCES}

Bassin, C., Laske, G. \& Masters, G., 2000. The current limits of resolution for surface wave tomography in north america, EOS, Trans. Am. geophys. Un., 81, F897.

Biggs, J., Nissen, E., Craig, T., Jackson, J. \& Robinson, D.P., 2010. Breaking up the hanging wall of a rift-border fault: the 2009 Karonga earthquakes, Malawi: the 2009 Karonga earthquakes, Malawi, Geophys. Res. Lett., 37, doi:10.1029/2010GL043179.

Bondár, I., Myers, S.C., Engdahl, E.R. \& Bergman, E.A., 2004. Epicentre accuracy based on seismic network criteria, Geophys. J. Int., 156, 483496.

Bondár, I. \& Storchak, D., 2011. Improved location procedures at the International Seismological Centre: improved location procedures at the ISC, Geophys. J. Int., 186, 1220-1244.

Chiou, S.-J. \& Youngs, R., 2014. Update of the Chiou and Youngs NGA model for the average horizontal component of peak ground motion and response spectra, Earthq. Spectra, 30(3), 1117-1153.

Chorowicz, J., 2005. The East African rift system, J. Afr. Earth Sci., 43, 379-410.

Craig, T.J., 2019. Accurate depth determination for moderate-magnitude earthquakes using global teleseismic data, J. geophys. Res., 124, 17591780 .

Craig, T.J., Jackson, J.A., Priestley, K. \& McKenzie, D., 2011. Earthquake distribution patterns in Africa: their relationship to variations in lithospheric and geological structure, and their rheological implications, Geophys. J. Int., 185, 403-434. 
Derras, B., Bard, P.Y., Cotton, F. \& Bekkouche, A., 2012. Adapting the neural network approach to PGA prediction: an example based on the KiK-net data, Bull. seism. Soc. Am., 102(4), 1446-1461.

Douglas, J., 2001. A comprehensive worldwide summary of strong-motion attenuation relationships for peak ground acceleration and spectral ordinates (1969 to 2000), ESEE Report 01-1, Department of Civil \& Environmental Engineering, Imperial College, London.

Ebinger, C.J., 1989. Geometric and kinematic development of border faults and accommodation zones, Kivu-Rusizi Rift, Africa, Tectonics, 8, 117133.

Franke, D. et al., 2015. The offshore East African Rift System: structural framework at the toe of a juvenile rift, Tectonics, 34, 2086-2104.

Gibbons, S. J., Antonovskaya, G., Asming, V., Konechnaya, Y. V., Kremenetskaya, E., Kværna, T., Schweitzer, J. \& Vaganova, N.V., 2016. The 11 October 2010 Novaya Zemlya earthquake: implications for velocity models and regional event location, Bull. seism. Soc. Am., 106(4), 1470-1481.

Husen, S. \& Hardebeck, J.L., 2010. Earthquake location accuracy, community online resource for statistical seismicity analysis, doi:10.5078/corssa55815573. Available at http://www.corssa.org.

International Seismological Centre, 2020a. On-line Bulletin, https://doi.or $\mathrm{g} / 10.31905 / \mathrm{D} 808 \mathrm{~B} 830$.

International Seismological Centre, 2020b. ISC-EHB dataset, https://doi.or g/10.31905/PY08W6S3.

Jerkins, A.E., Shiddiqi, H., Kværna, T., Gibbons, S.J., Schweitzer, J., Ottemöller, L. \& Bungum, H., 2020. The 30 June 2017 North Sea earthquake: location, characteristics, and context, Bull. seism. Soc. Am., 110(2), 937-952.

Kennett, B.L.N., Engdahl, E.R. \& Buland, R., 1995. Constraints on seismic velocities in the Earth from traveltimes, Geophys. J. Int., 122, 108-124.

Klimke, J., Franke, D., Mahanjane, E.S. \& Leitchenkov, G., 2018. Tie points for Gondwana reconstructions from a structural interpretation of the Mozambique Basin, East Africa and the Riiser-Larsen Sea, Antarctica, Solid Earth, 9, 25-37.

Laske, G., Masters, G., Ma, Z. \& Pasyanos, M., 2013. Update on CRUST1.0 - a 1-degree global model of Earth's crust, Geophys. Res. Abstr., 15, Abstract EGU2013-2658.

Leinweber, V.T. et al., 2013. The crustal structure of the Central Mozambique continental margin - wide-angle seismic, gravity and magnetic study in the Mozambique Channel, Eastern Africa, Tectonophysics, 599, 170-196.

Letort, J., Bollinger, L., Lyon-Caen, H., Guilhem, A., Cano, Y., Baillard, C. \& Adhikari, L.B., 2016. Teleseismic depth estimation of the 2015 Gorkha-Nepal aftershocks, Geophys. J. Int., 207, 1584-1595.

Letort, J., Guilbert, J., Cotton, F., Bondár, I., Cano, Y. \& Vergoz, J., 2015. A new, improved and fully automatic method for teleseismic depth estimation of moderate earthquakes $(4.5<\mathrm{M}<5.5)$ : application to the Guerrero subduction zone (Mexico), Geophys. J. Int., 201, 1834-1848.

Letort, J., Trilla, A.G., Ford, S.R. \& Myers, S.C., 2018. Multiobjective optimization of regional and teleseismic data to constrain the source of the 12 September $2016 \mathrm{Mw} 5.4$ earthquake in South Korea, Bull. seism. Soc. Am., 108, 175-187.

Letort, J., Vergoz, J., Guilbert, J., Cotton, F., Sebe, O. \& Cano, Y., 2014. Moderate earthquake teleseismic depth estimations: new methods and use of the comprehensive nuclear-test-ban treaty organization network data, Bull. seism. Soc. Am., 104, 593-607.

Lort, J.M., Limond, W.Q., Segoufin, J., Patriat, Ph., Delteil, J.R. \& Damotte, B., 1979. New seismic data in the Mozambique Channel, Mar. Geophys. Res., 4, 71-89.

Murphy, J. R. \& Barker, B. W., 2006. Improved focal-depth determination through automated identification of the seismic depth phases pP and sP, Bull. seism. Soc. Am., 96(4A), 1213-1229.

Oth, A. et al., 2017. KivuSNet: the first dense broadband seismic network for the Kivu Rift Region (Western Branch of East African Rift), Seismol. Res. Lett., 88, 49-60.

Pagani, M. et al., 2014. OpenQuake engine: an open hazard (and risk) software for the global earthquake model, Seismol. Res. Lett., 85(3), 692702.

Poggi, V., Durrheim, R., Tuluka, G.M., Weatherill, G., Gee, R., Pagani, M., Nyblade, A. \& Delvaux, D., 2017. Assessing seismic hazard of the East African Rift: a pilot study from GEM and AfricaArray, Bull. Earthq. Eng., 15, 4499-4529.

Pouclet, A., Bellon, H. \& Bram, K., 2016. The Cenozoic volcanism in the Kivu rift: assessment of the tectonic setting, geochemistry, and geochronology of the volcanic activity in the South-Kivu and Virunga regions, J. Afr. Earth Sci., 121, 219-246.

Skobelev, S.F., Hanon, M., Klerkx, J., Govorova, N.N., Lukina, N.V. \& Kazmin, V.G., 2004. Active faults in Africa: a review, Tectonophysics, 380, 131-137.

Stromeyer, D. \& Grunthal, G., 2009. Attenuation relationship of macroseismic intensities in Central Europe, Bull. seism. Soc. Am., 99, 554-565.

Theunissen, T. et al., 2018. Absolute earthquake locations using 3-D versus 1-D velocity models below a local seismic network: example from the Pyrenees, Geophys. J. Int., 212, 1806-1828.

Weston, J., Engdahl, E.R., Harris, J., Di Giacomo, D. \& Storchak, D.A., 2018. ISC-EHB: reconstruction of a robust earthquake data set, Geophys. J. Int., 214, 474-484.

Yang, Z. \& Chen, W.-P., 2008. Mozambique earthquake sequence of 2006: high-angle normal faulting in southern Africa, J. geophys. Res., 113, doi:10.1029/2007JB005419.

\section{SUPPORTING INFORMATION}

Supplementary data are available at $G J I$ online.

\section{supplementary_material.pdf}

Please note: Oxford University Press is not responsible for the content or functionality of any supporting materials supplied by the authors. Any queries (other than missing material) should be directed to the corresponding author for the paper. 